\title{
Reappraisal of Pneumoperitoneum After Percutaneous Endoscopic Gastrostomy
}

\author{
Won Young Park ${ }^{1}$, Tae Hee Lee ${ }^{1}$, Joon Seong Lee ${ }^{1}$, Su Jin Hong ${ }^{2}$, Seong Ran Jeon ${ }^{1}$, Hyun Gun Kim ${ }^{1}$ \\ Joo Young Cho ${ }^{1}$, Jin Oh Kim ${ }^{1}$, Jun Hyung Cho ${ }^{1}$, Sang Wook Lee ${ }^{3}$, Young Kwan Cho ${ }^{4}$ \\ Institute for Digestive Research, Digestive Disease Center, Soonchunhyang University Hospital', Seoul, Department of Internal Medicine, \\ Soonchunhyang University College of Medicine ${ }^{2}$, Bucheon, Department of Internal medicine, Sungbuk Central Hospital ${ }^{3}$, Seoul, Department \\ of Internal Medicine, Eulji General Hospital, Eulji University College of Medicine 4 , Seoul, Korea
}

Background/Aims: Pneumoperitoneum is recognized as a benign and self-limiting finding after the insertion of a percutaneous endoscopic gastrostomy (PEG) tube, while complicated pneumoperitoneum is rarely reported. The aim of this study was to reappraise pneumoperitoneum following PEG. Methods: We retrospectively reviewed 193 patients who underwent PEG from May 2008 to May 2014. All patients had a follow-up upright chest or simple abdominal radiograph after PEG. Pneumoperitoneum was quantified by measuring the height of the air column under the diaphragm and graded as small $(<2 \mathrm{~cm})$, moderate $(2-4 \mathrm{~cm})$, or large $(>4 \mathrm{~cm})$. Clinically significant signs were defined as fever, abdominal tenderness or leukocytosis occurring after PEG insertion. Results: Of the 193 study patients, 9 (4.6\%) had a pneumoperitoneum visualized by radiographic imaging, graded as small in 5 patients, moderate in 2 patients and large in 2 patients. Clinically significant signs were observed in 5 (55.5\%) patients with fever reported in 4 patients, abdominal tenderness in 4 patients and leukocytosis in 4 patients. The time to resolution of free air was 2-18 days. Two patients (22.2\%) with moderate or large pneumoperitoneum after PEG died from either pneumonia or septic shock. Conclusions: The clinical course of pneumoperitoneum after PEG is not always benign and self-limiting. These findings suggest that clinicians should not neglect a moderate or large pneumoperitoneum, particularly in patients who have an altered mental status or received antibiotics, since peritoneal irritation cannot be observed under these circumstances. (Intest Res 2015;13:313-317)

Key Words: Endoscopy, gastrointestinal; Pneumoperitoneum; Gastrostomy

\section{INTRODUCTION}

Percutaneous endoscopic gastrostomy (PEG) was first described in 1980 by Gauderer et al. ${ }^{1}$ Since then, PEG has become the method of choice for providing enteral access and nutritional support to patients who are unable to take oral feedings. ${ }^{2,3}$ Complications occur after PEG placement, including skin-site infection, acute hemorrhage, hematoma,

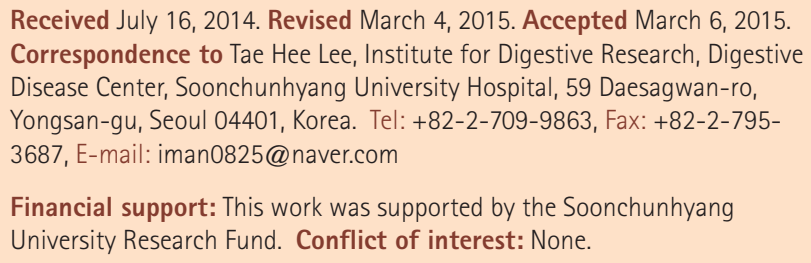

Financial support: This work was supported by the Soonchunhyang University Research Fund. Conflict of interest: None.

aspiration, and perforation. ${ }^{4-8}$ Pneumoperitoneum is an infrequent finding following insertion of $\mathrm{PEG},{ }^{4,8-10}$ and usually has a benign and self-limiting clinical course, ${ }^{4,10,11}$ while complicated pneumoperitoneum, such as bowel injury after PEG insertion, has been reported rarely., ${ }^{2,12-14}$ Thus, a reappraisal of pneumoperitoneum after PEG insertion is needed. In this study, we investigated the incidence and clinical significance of free air after PEG was performed at our institution over a 6-year period and provide a review of the English-language literature describing pneumoperitoneum after PEG tube placement.

\footnotetext{
๑ Copyright 2015. Korean Association for the Study of Intestinal Diseases. All rights reserved.

This is an Open Access article distributed under the terms of the Creative Commons Attribution Non-Commercial License (http://creativecommons.org/licenses/by-nc/4.0)

which permits unrestricted non-commercial use, distribution, and reproduction in any medium, provided the original work is properly cited.
} 


\section{METHODS}

\section{Patients}

The study was performed in the gastroenterology department at a tertiary referral care center. A retrospective chart review was carried out in 193 patients who underwent PEG placement at our institution by an experienced gastroenterologist from May 2008 to May 2014. The medical records of all patients were reviewed to assess the indication for PEG placement, radiographic studies, clinical symptoms, physical exams, laboratory data, antibiotic treatment, interventions, time to resolution of free air and feeding start time. Clinically significant signs were defined as fever, abdominal tenderness or leukocytosis occurring after PEG insertion.

This study was reviewed and approved by Soonchunhyang University Seoul Hospital institutional review board (2014-11-025-001).

\section{Pull Through Method for PEG Insertion}

Pull through method was performed for PEG insertion. Upon initiation of the procedure, a gastroscope was introduced by mouth and passed through the esophagus. The stomach was then insufflated and inspected. The duodenum was visualized in all patients. The endoscopist identified the suitable site in the anterior wall of the stomach using a focused external indentation or by transillumination. Li- docaine was injected locally into the subcutaneous tissue, and a trocar was inserted through the rectus sheath. Under direct visualization, a guide wire was then passed through the trocar, snared and pulled through the mouth with the endoscope. The PEG tube was firmly attached to the wire and an incision was then made in the skin to conform to the size of the PEG tube. The PEG tube was then pulled through the skin and secured with an external fastener 3-4 cm away from the bumper, depending on the abdominal wall thickness. The gastroscope was then reintroduced in all patients to assess complications and proper placement of the PEG tube. The gastrostomy tube was placed to drain until the next morning, when tube feeding was initiated.

\section{Pneumoperitoneum After PEG Insertion}

Within the first 24 hours after the procedure, all patients underwent an imaging study consisting of an upright chest or simple abdominal radiograph. The presence of free air in the right subdiaphragmatic area was diagnosed as pneumoperitoneum following PEG. Pneumoperitoneum was quantified by measuring the height of the air column under the diaphragm and was graded as small $(<2 \mathrm{~cm})$, moderate $(2-4 \mathrm{~cm})$ and large $(>4 \mathrm{~cm})$ (Fig. 1). If intraperitoneal air was identified, the patient's chest radiographs were followed until resolution. Time to resolution was calculated from the mean time that the pneumoperitoneum was first noted until the time of the first normal chest radiograph, in days.
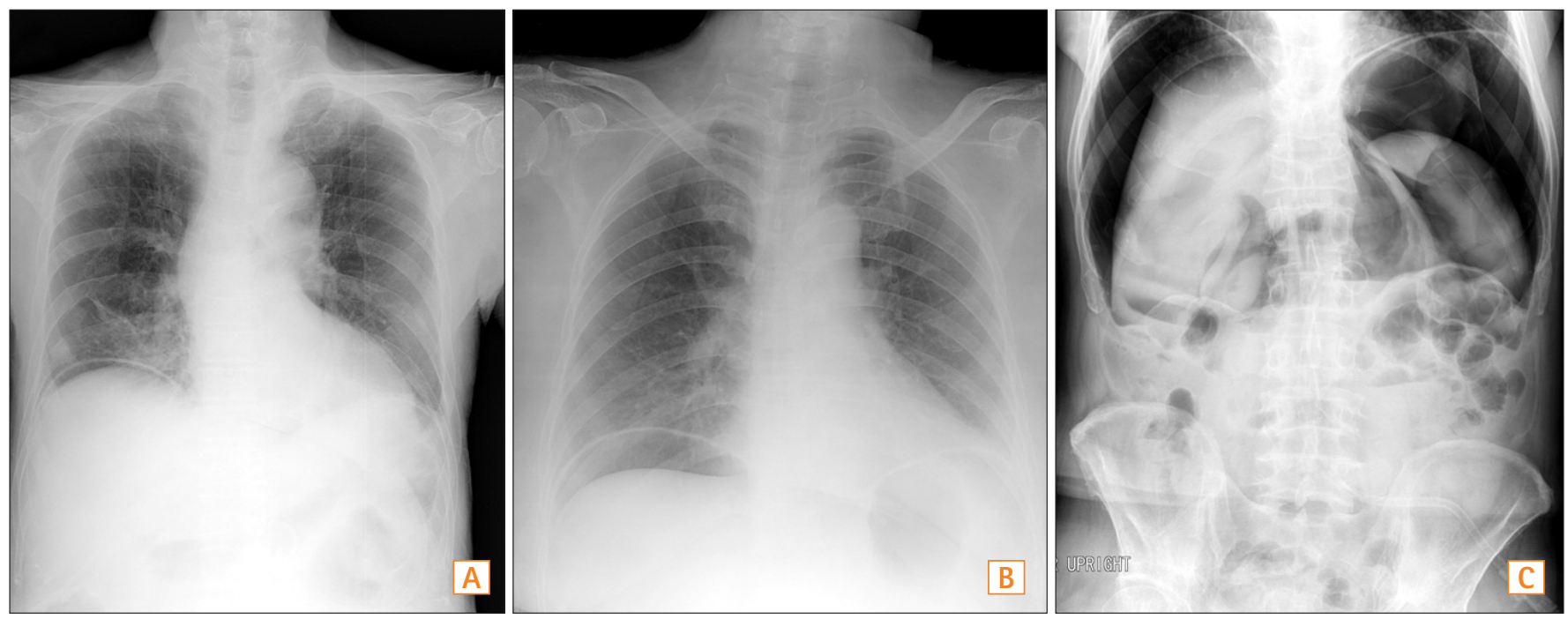

Fig. 1. Pneumoperitoneum grades following percutaneous endoscopic gastrostomy. (A) Small grade of pneumoperitoneum is defined when the height of the air column under the diaphragm is less than $2 \mathrm{~cm}$. (B) Moderate grade of pneumoperitoneum is defined when the height of the air column under the diaphragm ranges from 2 to $4 \mathrm{~cm}$. (C) Large grade of pneumoperitoneum is defined when the height of the air column under the diaphragm ranges is more than $4 \mathrm{~cm}$. 


\section{RESULTS}

\section{Baseline Characteristics of Patients Undergoing PEG}

Of the 193 patients undergoing PEG, 126 were males and 67 were females. There were 9 patients (4.6\%; 8 males, 1 female) with a pneumoperitoneum visualized by radiographic imaging. The median age was 72 years (range, $59-86$ years). The most common indication of PEG was stroke, which occurred in 7 pneumoperitoneum patients. Prophylactic antibiotics before PEG were administrated in 8 patients (88.8\%) with pneumoperitoneum.

\section{The Clinical Course of Patients With Pneumoperi- toneum After PEG}

The pneumoperitoneum grade was small in 5 patients, moderate in 2 patients and large in 2 patients. Fever developed in 4 patients (44.4\%), abdominal tenderness was observed in 4 patients (44.4\%) and leukocytosis was found in all patients. However, 5 patients had leukocytosis before insertion of the PEG tube because of pneumonia, a ventriculoperitoneal shunt, or urinary tract infection. Therefore, clinically significant signs were observed in 5 (55.5\%) patients. Empirical antibiotics were administered in 8 patients (88.8\%). Tube feeding was begun in 7 patients $(77.7 \%)$ before resolution of free air, although feeding was stopped in 1 patient because of nausea and vomiting. The range of time to resolution of free air was 2-18 days. Five of 9 patients $(55.5 \%)$ had a small pneumoperitoneum, and 2 of these patients had free air on the 72 hours follow-up radiograph. Two of 9 patients (22.2\%) had moderate free air, which persisted in 2 patients after 72 hours, and 2 of 9 patients $(22.2 \%)$ had a large amount of free air that persisted after 72 hours. Two patients (22.2\%) died after PEG due to aspiration pneumonia or septic shock (Table 1).

\section{DISCUSSION}

Table 2 shows the variable incidence of pneumoperitoneum following PEG tube placement. The incidence estimates for pneumoperitoneum in the literature range from 4.7\%-55.6\% ${ }^{8,13}$ Differences in methodology, expertise with the PEG technique, or endoscopic equipment explain some of the variability in the incidence. An imaging study after insertion of PEG is usually performed to assess complications such as pneumonia or fever. Retrospective studies, which were not designed to specifically evaluate the incidence of pneumoperitoneum, might underestimate the incidence. CT is superior to a chest $\mathrm{x}$-ray in detecting the presence of pneumoperitoneum. ${ }^{15}$ In a study describing PEG-induced pneumoperitoneum, CT revealed the presence of free air in 6 patients who had no evidence of pneumoperitoneum on the chest $\mathrm{x}$-ray. ${ }^{12}$ Based on the results in Table 2, the incidence of pneumoperitoneum has decreased over time, probably due

Table 1. The Clinical Course of Patients With Pneumoperitoneum After Percutaneous Endoscopic Gastrostomy (PEG)

\begin{tabular}{|c|c|c|c|c|c|c|c|c|c|c|c|}
\hline Case & Gender & Age & Indication & Grade & Fever & $\begin{array}{l}\text { Abdominal } \\
\text { tenderness }\end{array}$ & Leukocytosis & $\begin{array}{c}\text { Antibiotics } \\
\text { (Prophylactic } \\
\text { antibiotics) }\end{array}$ & $\begin{array}{c}\text { Diet } \\
\text { start } \\
\text { (days) } \\
\end{array}$ & $\begin{array}{c}\text { Time to } \\
\text { resolution } \\
\text { (days) }\end{array}$ & $\begin{array}{l}\text { Death } \\
\text { (Cause of } \\
\text { death) }\end{array}$ \\
\hline 1 & Male & 84 & Stroke & Moderate & Yes & Yes & Yes $^{*}$ & Yes (Yes) & 8 & 6 & No \\
\hline 2 & Male & 67 & Stroke & Small & No & No & Yes $^{*}$ & No (No) & 2 & 3 & No \\
\hline 3 & Male & 68 & Stroke & Large & No & No & Yes $^{*}$ & Yes (Yes) & 2 & 18 & No \\
\hline 4 & Male & 86 & Stroke & Small & No & No & Yes $^{*}$ & Yes (Yes) & 2 & 2 & No \\
\hline 5 & Male & 81 & $\begin{array}{l}\text { Hypoxic brain } \\
\text { damage }\end{array}$ & Small & No & No & Yes $^{*}$ & Yes (Yes) & 2 & 7 & No \\
\hline 6 & Male & 63 & Stroke & Small & No & Yes & Yes & Yes (Yes) & 2 & 6 & No \\
\hline 7 & Male & 76 & $\begin{array}{l}\text { Oropharyngeal } \\
\text { cancer }\end{array}$ & Large & Yes & Yes & Yes & Yes (Yes) & 12 & 18 & $\begin{array}{l}\text { Yes } \\
\text { (Septic shock) }\end{array}$ \\
\hline 8 & Female & 59 & Stroke & Moderate & Yes & Yes & Yes & Yes (Yes) & $2^{+}$ & 7 & $\begin{array}{l}\text { Yes } \\
\text { (Aspiration } \\
\text { pneumonia) }\end{array}$ \\
\hline 9 & Male & 61 & Stroke & Small & Yes & No & Yes & Yes (Yes) & 2 & 8 & No \\
\hline
\end{tabular}

*Leukocytosis was present before insertion of the PEG tube due to pneumonia, ventriculoperitoneal shunt infection or urinary tract infection.

${ }^{+}$Initial feeding was stopped because of nausea and vomiting and restarted 13 days after PEG insertion. 
Table 2. Percutaneous Endoscopic Gastrostomy (PEG) Case Series and the Incidence of Pneumoperitoneum

\begin{tabular}{|c|c|c|c|c|c|c|}
\hline Author & Yr & $\begin{array}{l}\text { Total study } \\
\text { population }\end{array}$ & Pneumoperitoneum & $\begin{array}{l}\text { Significant } \\
\text { clinical sign* }\end{array}$ & Surgery & Death \\
\hline Park et al. (present study) & 2014 & 193 & $9(4.6 \%)$ & $5(2.6 \%)$ & 0 & $2(1.0 \%)$ \\
\hline Milanchi and Allins ${ }^{13}$ & 2007 & 85 & $4(4.7 \%)$ & 0 & 1 (perforated colon) & 0 \\
\hline Alley et al. ${ }^{9}$ & 2007 & 120 & $8(6.6 \%)$ & 0 & $0^{\dagger}$ & \\
\hline Dulabon et al. ${ }^{12}$ & 2002 & $119^{\S}$ & $10(8.4 \%)$ & $4(3.4 \%)$ & $6^{\|}$ & 0 \\
\hline Pidala et al. ${ }^{17}$ & 1992 & 30 & $7(23.3 \%)$ & 0 & 0 & 0 \\
\hline Wojtowycz et al. ${ }^{8}$ & 1988 & 18 & $10(55.6 \%)$ & 0 & 0 & 0 \\
\hline Gottfried et al. ${ }^{4}$ & 1986 & 17 & $6(35.3 \%)$ & 0 & 0 & 0 \\
\hline
\end{tabular}

*Significant clinical signs included fever, abdominal tenderness, and leukocytosis.

${ }^{\dagger}$ Four of these patients had a duodenal perforation (1), liver laceration (1) and leakage (2).

${ }^{\ddagger}$ Colocutanoeus fistula was a late complication in 2 patients without evidence of pneumoperitoneum.

${ }^{\S}$ Included 3 cases of percutaneous gastrostomy performed by radiologists.

"Three of these patients had colocutaneous fistula and one had dislodgement of the PEG tube.

'Gastric colic fistula and intraperitoneal gastric leakage were found.

to improvements in endoscopic technique or equipment.

The etiology of pneumoperitoneum after PEG insertion is probably related to the high intragastric air pressure generated by the endoscope in association with needle puncture of the gastric wall and stomach. Air may escape through the stomach during needle puncture and the passage of the PEG tube through the abdominal wall. ${ }^{4}$ In complicated pneumoperitoneum following PEG tube placement, the most common reported diagnosis was colocutaneous fistula or colon injury. Colocutaneous fistula results from interposition of bowel, usually splenic flexure, between the anterior abdominal wall and gastric wall. ${ }^{16}$ Inadequate or excessive gastric insufflation, inappropriate transillumination, or non-visible focal invagination of anterior gastric wall upon external palpation are related to colon injury. ${ }^{16}$ These findings support the hypothesis that technical problems with PEG insertion might be related to the development of complicated pneumoperitoneum.

Posterior gastric perforations, with defects up to $1.5 \mathrm{~cm}$, usually have a benign course, while anterior perforations generally require surgery. ${ }^{4}$ Many patients who are candidates for PEG have severe morbidity. Given these findings, pneumoperitoneum after PEG insertion is likely to have clinically significant signs such as fever, abdominal tenderness, or leukocytosis. However, most patients are asymptomatic. Moreover, some patients undergoing PEG tube insertion may receive broad-spectrum antibiotics because of co-exis- tent infection (e.g., aspiration pneumonia and urinary tract infection). In these patients, clinically significant signs might be masked, and complicated pneumoperitoneum could be missed. Furthermore, peritoneal irrigational signs might be overlooked due to altered mental status (e.g., patients after cranial neurosurgery) or long-term sedation (e.g., patients receiving mechanical ventilation). In the present study, pneumoperitoneum with clinically significant signs was observed in 5 (55.5\%) of 9 patients. Furthermore, 2 (22.2\%) of 9 patients died due to aspiration pneumonia and septic shock.

Unless accompanied by signs or symptoms of peritoneal inflammation, pneumoperitoneum does not lead to further diagnostic or therapeutic interventions. ${ }^{4,10,11}$ In a study of PEG in intensive care patients, 1 in 4 patients who had pneumoperitoneum had neither clinically significant signs nor signs of peritoneal irritation. ${ }^{13}$ The primary indication of complicated pneumoperitoneum is a large pneumoperitoneum that does not resolve within 72 hours. In our study, the range of time to resolution of free air was 2-18 days. Another study also reported that a moderate or large pneumoperitoneum usually persists after 72 hours. ${ }^{11}$ Given our results and previous reports, ${ }^{2,12-14}$ complicated pneumoperitoneum cannot be predicted by the time to resolution and is unlikely to occur in patients with a small pneumoperitoneum.

Our study showed that the clinical course of pneumoperitoneum following PEG is not always benign and selflimiting. Persistence of free air after 72 hours was seen in 6 
of the 9 patients (66.6\%). These findings suggest that time to resolution is a poor indicator for monitoring evidence of peritonitis. Death did not occur in any patient with a small pneumoperitoneum, but 2 patients with moderate or large pneumoperitoneum died. These findings suggest that clinicians should not neglect a moderate or large pneumoperitoneum, particularly in patients who have an altered mental status or who have received antibiotics, since peritoneal irritation cannot be observed under these circumstances.

\section{REFERENCES}

1. Gauderer MW, Ponsky JL, Izant RJ, Jr. Gastrostomy without laparotomy: a percutaneous endoscopic technique. J Pediatr Surg 1980;15:872-875.

2. Blum CA, Selander C, Ruddy JM, Leon S. The incidence and clinical significance of pneumoperitoneum after percutaneous endoscopic gastrostomy: a review of 722 cases. Am Surg 2009;75:39-43.

3. Seo YJ, Cha JM, Lee JI, et al. The improvement of nutritional support with percutaneous endoscopic gastrostomy. Intest Res 2013;11:120-126.

4. Gottfried EB, Plumser AB, Clair MR. Pneumoperitoneum following percutaneous endoscopic gastrostomy. A prospective study. Gastrointest Endosc 1986;32:397-399.

5. McClave SA, Chang WK. Complications of enteral access. Gastrointest Endosc 2003;58:739-751.

6. Stassen WN, McCullough AJ, Marshall JB, Eckhauser ML. Percutaneous endoscopic gastrostomy: another cause of "benign" pneumoperitoneum. Gastrointest Endosc 1984;30:296-298.

7. Wills JS, Oglesby JT. Percutaneous gastrostomy. Radiology 1983;149:449-453.
8. Wojtowycz MM, Arata JA, Jr., Micklos TJ, Miller FJ, Jr. CT findings after uncomplicated percutaneous gastrostomy. AJR Am J Roentgenol 1988;151:307-309.

9. Alley JB, Corneille MG, Stewart RM, Dent DL. Pneumoperitoneum after percutaneous endoscopic gastrostomy in patients in the intensive care unit. Am Surg 2007;73:765-767; discussion 768.

10. Hillman KM. Pneumoperitoneum - a review. Crit Care Med 1982;10:476-481.

11. Wiesen AJ, Sideridis K, Fernandes A, et al. True incidence and clinical significance of pneumoperitoneum after PEG placement: a prospective study. Gastrointest Endosc 2006;64:886889.

12. Dulabon GR, Abrams JE, Rutherford EJ. The incidence and significance of free air after percutaneous endoscopic gastrostomy. Am Surg 2002;68:590-593.

13. Milanchi S, Allins A. Early pneumoperitoneum after percutaneous endoscopic gastrostomy in intensive care patients: sign of possible bowel injury. Am J Crit Care 2007;16:132-136.

14. Strodel WE, Lemmer J, Eckhauser F, Botham M, Dent T. Early experience with endoscopic percutaneous gastrostomy. Arch Surg 1983;118:449-453.

15. Stapakis JC, Thickman D. Diagnosis of pneumoperitoneum: abdominal CT vs. upright chest film. J Comput Assist Tomogr 1992;16:713-716.

16. Schrag SP, Sharma R, Jaik NP, et al. Complications related to percutaneous endoscopic gastrostomy (PEG) tubes. A comprehensive clinical review. J Gastrointestin Liver Dis 2007;16:407418.

17. Pidala MJ, Slezak FA, Porter JA. Pneumoperitoneum following percutaneous endoscopic gastrostomy. Does the timing of panendoscopy matter? Surg Endosc 1992;6:128-129. 